\title{
Usos de la Internet y teléfono celular asociados a situaciones de riesgo de explotación sexual de adolescentes
}

\author{
Rafael Gutiérrez,' Leticia Vega, ${ }^{1}$ Abraham Ernesto Rendón'
}

Artículo original

\section{SUMMARY}

This paper reports on a research project designed to identify the uses of the Internet and cellular telephony that could place children at risk of contact with situations associated with sexual exploitation: hooking up on line, consumption of pornography and the production of humiliating, sexualized images. The questionnaires were administered to 147 adolescents with an average age of 13 years and 3 months.

\section{Results}

A total of $66.2 \%$ of the boys and $71.4 \%$ of the girls reported having Facebook, followed by Hi5 (69\%) and My Space (43.3\%). Teenagers were observed to provide their real names $164.7 \%$ of boys and $78 \%$ of girls) and actual ages in social networks. A total of $79.6 \%$ of the respondents reported that they liked to talk on Chat or Messenger, while a significant percentage $(64.1 \%)$ had done so with strangers. A total of $53.1 \%$ of the population reported having met a friend with a sexualized image of their person through a cell phone (28.6 of boys and $11.6 \%$ of girls). These images were usually shared with friends (reported by $77.1 \%$ of boys and $62.8 \%$ of girls). But others were uploaded onto the Internet $(34.3 \%$ of boys and $37.2 \%$ of women) and a minority were sold ( $8.6 \%$ of boys and $2.3 \%$ of girls). The paper indicates that true information on the person provided with no restrictions whatsoever by adolescents in social networks and their interaction with strangers in chats are indicators of unsafe Web browsing. Qualitative research results indicate that these acts occur when teenagers are seeking popularity. The paper also discusses teenagers' consumption of pornography as a type of manhood that is "hot" by nature and shows that the production of sexualized images occurs in contexts where amusement is combined with sexual transgression.

Key words: Child sexual exploitation, Internet, cell phone.

\section{RESUMEN}

Se reporta una investigación que tuvo por objetivo identificar los usos de la Internet y la telefonía celular que podrían poner a niñas y niños en riesgo de contacto con situaciones asociadas a la explotación sexual: enganchamiento en línea, consumo de pornografía y producción de imágenes sexualizadas y humillantes. Se aplicaron cuestionarios a 147 adolescentes de 13 años y tres meses de edad en promedio.

\section{Resultados}

El $66.2 \%$ de los hombres y el $71.4 \%$ de las mujeres reporta tener Facebook, seguido de Hi5 (69\%) y My Space (43.3\%). Se observa que los adolescentes de ambos sexos proporcionan su nombre $164.7 \%$ de los hombres y $78 \%$ de las mujeres) y edades reales en las redes sociales. El $79.6 \%$ de las y los encuestados reportan que les agrada platicar en el Chat o el Messenger. Un porcentaje importante (el 64.1\%) lo ha llevado a cabo con personas desconocidas. El $53.1 \%$ de la población reportó conocer a algún amigo con una imagen sexualizada de su persona a través de un celular $(28.6 \%$ hombres y $11.6 \%$ mujeres). Estas imágenes fueron compartidas con los amigos (reportado por el $77.1 \%$ de los hombres y el $62.8 \%$ de las mujeres), pero otras fueron subidas a la Internet $34.3 \%$ hombres y $37.2 \%$ mujeres) y una minoría se vendió ( $8.6 \%$ hombres y $2.3 \%$ mujeres). El trabajo señala que la información verídica de la persona proporcionada sin restricción alguna por los adolescentes en las redes sociales y su interacción con desconocidos en chats, son indicadores de navegación insegura en la Internet. La investigación cualitativa indica que dichos actos ocurren cuando las adolescentes buscan popularidad. Además, el documento discute el consumo de pornografía de los adolescentes como reproducción de un tipo de hombría "caliente por naturaleza" y señala que la producción de imágenes sexualizadas ocurre en contextos donde se combina la diversión con la transgresión sexual.

Palabras clave: Explotación sexual, Internet, teléfono celular.

Dirección de Investigaciones Epidemiológicas y Psicosociales del Instituto Nacional de Psiquiatría Ramón de la Fuente Muñiz.

Correspondencia: Mtra. Leticia Vega. Dirección de Investigaciones Epidemiológicas y Psicosociales, INPRFM. Calz. México-Xochimilco 101, San Lorenzo Huipulco, Tlalpan, 14370, México, DF. Tel. 4160-5149. E-mail:vegahl@imp.edu.mx

Recibido primera versión: 29 de febrero de 2012. Segunda versión: 21 de marzo de 2012. Aceptado: 9 de agosto de 2012. 


\section{INTRODUCCIÓN}

Los principales resultados de distintas investigaciones de los usos de la red de Internet y de la telefonía celular, ${ }^{1-12}$ indican que niños y niñas de distintas partes de Europa y de los Estados Unidos están expuestos a situaciones de riesgo de explotación sexual, las cuales incluyen:

a) El enganchamiento en línea con el fin de explotarles sexualmente. Para tal efecto, los depredadores sexuales, casi siempre hombres adultos, suelen construir una relación de confianza con el niño/a, obtener información verídica de la víctima, reducir las inhibiciones de ésta, llevarle a conversaciones y acciones íntimas y a citas cara a cara para explotarles sexualmente. El enganchamiento en línea es un proceso que incluye amenazas, chantaje, traición y el daño psicológico de la víctima.

b) La exposición de niñas y niños a material sexual para uso exclusivo de los adultos, como la pornografía. Al respecto se ha reportado que niños y niñas se sienten perturbados cuando materiales pornográficos ingresan en su entorno sin que los hayan pedido. Bajo determinadas condiciones de vulnerabilidad social (como el abuso sexual previo), la exposición a la pornografía puede tener como resultado una combinación de efectos en quien la ve: dependencia/adicción, escalada, desensibilización e imitación.

c) La producción de imágenes sexualizadas y humillantes de niñas y niños por medio del uso de cámaras de fotografía y de video por parte de adolescentes, es un fenómeno recientemente reportado entre adolescentes estadounidenses. Estas imágenes suelen ser compartidas con otros adolescentes, distribuidas y subidas a la red de Internet con y sin el consentimiento de las personas fotografiadas o videograbadas. Como consecuencia de la socialización de esas imágenes las víctimas pueden sufrir efectos colaterales tales como culpa, depresión, baja autoestima, dificultades para concentrarse, conductas agresivas e ira reprimida y desconfianza.

Los resultados anteriores permiten tener una apreciación del problema en determinadas sociedades europeas y de América del norte. En México hay más de 12 millones de internautas entre los seis y los 17 años de edad, ${ }^{13}$ y se carece de investigaciones que permitan comprender los usos de las nuevas tecnologías desde las perspectivas de sus principales actores así como estimar de manera confiable los riesgos asociados y los factores que los propician y desalientan.

Aquí reportamos los resultados de una investigación desarrollada en el año 2011, la cual tuvo por objetivo identificar los usos de la Internet y de los teléfonos celulares que pueden poner a niñas y niños en riesgo de contacto con situaciones asociadas al enganchamiento en línea, el consumo de pornografía y la producción y difusión de imágenes sexualizadas.

\section{MÉTODO}

Del 2 de mayo al 30 de junio del año 2011 se llevó a cabo la aplicación de 147 cuestionarios con el objetivo de observar y describir el uso de la Internet y de los teléfonos celulares en alumnos de educación media básica de los municipios de Cuautitlán Izcalli, Cuautitlán México, Ecatepec y Tlalnepantla, todos pertenecientes a la zona conurbada del Estado de México con la capital del país.

Se trata de la zona metropolitana más poblada del país y de Latinoamérica pues suma poco más de 11 millones de habitantes distribuidos en 59 Municipios, entre los que destaca Ecatepec por ser el municipio más poblado (1 734701 habitantes) y el municipio de Tlalnepantla (660953 habitantes) por su desarrollo urbano e industrial. Todos estos municipios pertenecen al Estado de México, el cual en distintos momentos de los últimos 10 años, ha ocupado los primeros cinco lugares con mayor número de infanticidios a nivel nacional; ${ }^{14,15}$ el tercer lugar de delitos cometidos a mano armada; ${ }^{16}$ el segundo lugar en hogares con al menos una víctima ${ }^{16,17}$ y el segundo lugar por su alta prevalencia e incidencia delictiva; ${ }^{16,17}$ el primer lugar en proporción de mujeres maltratadas a lo largo de su relación de pareja y el segundo lugar de violencia sexual contra las mujeres en espacios comunitarios o públicos ${ }^{18}$ así como el primer lugar en feminicidios. De acuerdo con algunos autores, ${ }^{19}$ la violencia que ahoga al Estado de México es consecuencia, por lo menos en parte, de la corrupción y falta de coordinación entre autoridades gubernamentales y organizaciones no gubernamentales para enfrentarla integralmente.

Autoridades de los DIF Estado de México y Municipales de la zona conurbada contactaron a las instituciones escolares donde se realizaría la aplicación de estos cuestionarios. Se contó con la participación de 18 a 49 alumnos y/o alumnas por centro educativo, para lo cual se trató de seleccionar aleatoriamente a alumnos de los diferentes grados académicos, intentando cubrir una cuota de 40 participantes.

El cuestionario que se aplicó en los cuatro municipios consta de siete secciones distribuidas de la siguiente manera: datos generales; antecedentes escolares; antecedentes familiares; antecedentes sexuales y usos de la Internet.

Dicho cuestionario se aplicó en cuatro escuelas secundarias en formato de autoaplicación con una duración de 30 a 60 minutos por institución. La aplicación fue realizada de la misma forma en los cuatro municipios. De todas/os los participantes se obtuvo el consentimiento informado, el cual garantizó confidencialidad y anonimato. A todas/os las/os informantes se les ofreció protección y atención en el caso de que lo solicitarán o lo requirieran con urgencia. Las autoridades del DIF Estado de México y las de los DIF Municipales estuvieron al pendiente de todos los participantes y alertas para recibir la información de los casos que aquí se reportan. 


\section{RESULTADOS}

\section{Características psicosociales de los participantes}

En la aplicación hubo 147 participantes (70 mujeres y 77 hombres). La media de edad es de 13.35 años con una desviación estándar de 0.928 . La persona más joven tiene 12 años y la más grande 16. La media de edad de los hombres es de 13.44 años con una desviación estándar de 1.006. La media de edad de las mujeres es de 13.26 años con una desviación estándar de 0.829 . El $70.1 \%$ de las y los participantes nacieron dentro del Estado de México, $21.8 \%$ en el Distrito Federal y $3.4 \%$ en otras entidades federativas (el resto no respondió el reactivo). El $64.6 \%$ vive en una familia nuclear con padre/padrastro, madre/madrastra y hermanos, el resto (35.4\%) vive en diversos arreglos familiares; la mayoría de las familias se encuentran conformadas por seis integrantes.

Se puede decir que muy pocas de las familias de nuestros informantes carecen de instrucción formal (1.4\%). El $36.7 \%$ de los padres y el $33.3 \%$ de las madres de nuestros informantes estudiaron la secundaria y el $21.1 \%$ y $19 \%$, respectivamente, cuentan con estudios de bachillerato. Un porcentaje menor de los padres ( $11.6 \%$ de los padres y el $18.4 \%$ de las madres) tiene la primaria como nivel máximo escolar.

Según nuestros informantes la mayoría de sus padres o madres trabajan en el sector terciario $(61.9 \%$ de los padres y $34.7 \%$ de las madres). El $5 \%$ de las madres y $18.4 \%$ de los padres trabaja en el sector secundario. La percepción de la economía familiar es similar por sexo y por municipio, siendo la categoría de economía media aquella que es más percibida por los participantes.

Cuando aplicamos el cuestionario, cerca del $12.2 \%$ de las y los participantes había iniciado su vida sexual (13 hombres y cinco mujeres), siendo la edad promedio de inicio los 12.8 años. Las principales personas con las que iniciaron su vida sexual fueron la novia o novio (ocho hombres y cinco mujeres) y primas (dos hombres). Un muchacho reporta haber sido obligado a mantener relaciones sexuales con otras personas a la edad de 13 años.

Además encontramos que el $46.3 \%$ de las y los informantes cursaban el primer grado de secundaria, el $42.2 \%$ el segundo grado y el $11.6 \%$ el tercero. Un $7.5 \%$ de casos (cuatro hombres y siete mujeres) había dejado de estudiar en algún momento, siendo las principales causas aquellas relacionadas con los problemas familiares.

\section{Uso de Internet, teléfonos celulares $y$ riesgos asociados}

El $70.7 \%$ de los informantes cuenta con computadora en casa y el $76.9 \%$ tiene celular; no se observan diferencias estadísticamente significativas entre hombres y mujeres.
Aunque no todos tienen computadora y celular propios, el 100\% utiliza la Internet, siendo los sitios fuera de casa (cibercafés, escuela y con amigos) los más visitados para utilizar este servicio (61.9\%); el resto de las y los participantes lo utiliza en casa (36.1\%). El número de horas utilizadas al día en la Internet por las y los participantes es de 2.58 en hombres y 2.68 en mujeres. El $49.4 \%$ de los hombres y el $51.4 \%$ de las mujeres utilizan la red cuatro o más veces a la semana. Se observan diferencias estadísticamente significativas* en el número de horas mínimas y máximas utilizadas a la semana entre la población que usa la Internet en casa (14.55 horas y 17.77 horas respectivamente) en comparación a las personas que lo utilizan fuera de la misma (7.16 horas mínimas y 8.87 horas máximas a la semana).

Las principales personas que saben utilizar el equipo de cómputo en la familia son los hermanos mayores (54.4\% en los adolescentes y $54.3 \%$ en las adolescentes), en menor medida los padres aparecen como usuarios de las computadoras. El 37.7\% de los hombres y el $31.4 \%$ de las mujeres reporta que sus padres nunca los supervisan cuando se encuentran utilizando Internet.

De acuerdo a los reportes de las y los participantes son los hermanos mayores ( $46.8 \%$ en hombres y $42.9 \%$ en mujeres) quienes utilizan en mayor medida el mismo equipo de cómputo que las y los adolescentes.

La mayoría de los hombres (75.3\%) y de las mujeres $(84.3 \%)$ usa Internet para realizar las tareas escolares. Sin embargo más mujeres que hombres usan la web para chatear (68.8\% en hombres y $84.3 \%$ en mujeres), ver videos de música (55.8\% en hombres y $75.7 \%$ en mujeres) y platicar en el Messenger ( $51.9 \%$ en hombres y $57.1 \%$ en mujeres) así como para bajar fotos de artistas y videos de grupos de música y ver capítulos de TV.

a) Usos de Internet que ponen en riesgo de enganchamiento en línea: Más niñas que niños usan las redes sociales con sus nombres y edades reales. El 66.2\% (51) de los hombres y el $71.4 \%$ (50) de las mujeres reporta tener alguna página personal, siendo Facebook el servicio más utilizado por esta población (97.2\%), seguido de Hi5 (69\%) y My Space (43.3\%). En el cuadro 1 se observa que la mayoría de los niños $(64.7 \%$ ) y de las niñas (78\%) proporcionan su nombre real. Sin embargo, más niñas que niños dicen su edad verdadera ( $45.1 \%$ niños y $72 \%$ niñas) y el nombre y edad verdaderos de sus amigos ( $46 \%$ niñas y $25.4 \%$ niños). Más niñas que niños proporcionan información falsa del nombre de familiares (56\% de las niñas y $29 \%$ de los niños), del lugar dónde viven ( $52 \%$ ellas y $35.2 \%$ ellos) y de los lugares que frecuentan ( $64 \%$ de aquellas y $21 \%$ de éstos). También llama la atención que más niños $(60.8 \%)$ que niñas $(30 \%)$ suban fotografías reales de su persona y proporcionen información verídica acerca de sus gus-

${ }^{*} \dagger(141)=3.557, p \leq 0.05$ para tiempos mínimos; $\dagger(141)=3.694, p \leq 0.05$ para tiempos máximos. 
Cuadro 1. Información verdadera y falsa que colocan los participantes en sus páginas personales. Comparación por sexo

\begin{tabular}{|c|c|c|c|}
\hline & & $\begin{array}{l}\text { Hombres } \\
(\mathrm{n}=51)\end{array}$ & $\begin{array}{l}\text { Mujeres } \\
(\mathrm{n}=50)\end{array}$ \\
\hline Fotografía personal & $\begin{array}{l}\mathrm{V} \\
\mathrm{F}\end{array}$ & $\begin{array}{l}60.8 \% \\
29.4 \%\end{array}$ & $\begin{array}{l}30.0 \% \\
24.0 \%\end{array}$ \\
\hline Nombre personal & $\begin{array}{l}\text { V } \\
F\end{array}$ & $\begin{array}{l}64.7 \% \\
19.6 \%\end{array}$ & $\begin{array}{l}78.0 \% \\
22.0 \%\end{array}$ \\
\hline Edad de la persona & $\begin{array}{l}V \\
F\end{array}$ & $\begin{array}{l}45.1 \% \\
31.4 \%\end{array}$ & $\begin{array}{l}72.0 \% \\
28.0 \%\end{array}$ \\
\hline Nombre de la escuela & $\begin{array}{l}\text { V } \\
F\end{array}$ & $\begin{array}{l}47.0 \% \\
29.4 \%\end{array}$ & $\begin{array}{l}62.0 \% \\
32.0 \%\end{array}$ \\
\hline Nombre y edad de las amistades & $\begin{array}{l}\text { V } \\
F\end{array}$ & $\begin{array}{l}25.4 \% \\
39.2 \%\end{array}$ & $\begin{array}{l}46.0 \% \\
42.0 \%\end{array}$ \\
\hline Nombre y edad de los familiares & $\begin{array}{l}V \\
F\end{array}$ & $\begin{array}{l}21.6 \% \\
29.4 \%\end{array}$ & $\begin{array}{l}40.0 \% \\
56.0 \%\end{array}$ \\
\hline Nombre del lugar de residencia & $\begin{array}{l}V \\
F\end{array}$ & $\begin{array}{l}25.5 \% \\
35.2 \%\end{array}$ & $\begin{array}{l}38.0 \% \\
52.0 \%\end{array}$ \\
\hline Nombre de lugares frecuentados & $\begin{array}{l}V \\
F\end{array}$ & $\begin{array}{l}19.6 \% \\
21.6 \%\end{array}$ & $\begin{array}{l}44.0 \% \\
64.0 \%\end{array}$ \\
\hline Descripción física & $\begin{array}{l}V \\
F\end{array}$ & $\begin{array}{l}21.6 \% \\
45.1 \%\end{array}$ & $\begin{array}{l}44.0 \% \\
40.0 \%\end{array}$ \\
\hline Gustos, pasatiempos y actividades & $\begin{array}{l}V \\
F\end{array}$ & $\begin{array}{l}56.9 \% \\
29.4 \%\end{array}$ & $\begin{array}{l}30.0 \% \\
20.0 \%\end{array}$ \\
\hline
\end{tabular}

Notas: $V=$ Verdadera; $F=$ Falsa.

tos, pasatiempos, actividades, etc. $(56.9 \%$ niños, 30\% niñas).

El $70.6 \%$ de los hombres y el $70 \%$ de las mujeres que cuentan con página personal señalan que cualquier persona puede revisar su perfil. El $79.6 \%$ de las y los encuestados reportan que les agrada platicar en el Chat o el Messenger. De esta muestra un porcentaje importante (el 64.1\%) lo ha llevado a cabo con personas desconocidas. No se observan diferencias estadísticamente significativas, por lo que hombres y mujeres han hablado con extraños en proporción similar.

Cuando las y los participantes platican con desconocidos (62.5\% de los hombres y $65.5 \%$ de las mujeres) se observa que el $27.5 \%$ de las adolescentes y el $20 \%$ de

Cuadro 2. Datos que socializan las y los participantes cuando platican con desconocidos vía chat o Messenger. Comparación por sexo

\begin{tabular}{llrr}
\hline & & $\begin{array}{r}\text { Hombres } \\
(\mathrm{n}=35)\end{array}$ & $\begin{array}{r}\text { Mujeres } \\
(\mathrm{n}=40)\end{array}$ \\
\hline Nombre & Siempre & $22.8 \%$ & $20.0 \%$ \\
\multirow{4}{*}{ Edad } & Nunca & $28.5 \%$ & $45.0 \%$ \\
& Siempre & $25.7 \%$ & $15.0 \%$ \\
Sexo & Nunca & $37.1 \%$ & $50.0 \%$ \\
\multirow{3}{*}{ Nombre de la escuela } & Siempre & $20.0 \%$ & $27.5 \%$ \\
& Nunca & $40.0 \%$ & $30.0 \%$ \\
Lugar de residencia & Siempre & $5.7 \%$ & $5.0 \%$ \\
& Nunca & $54.3 \%$ & $70.0 \%$ \\
& Siempre & $8.6 \%$ & $5.0 \%$ \\
& Nunca & $57.1 \%$ & $72.5 \%$ \\
\hline
\end{tabular}

los adolescentes menciona su sexo real (cuadro 2), y el $22.8 \%$ de los hombres y el $20 \%$ de las mujeres mencionan su nombre real. Más hombres que mujeres menciona su edad real ( $25.7 \%$ en los jóvenes y $15 \%$ en las jóvenes). Más niñas que niños se muestran precavidos al participar en foros y chats. Por ejemplo, la mayoría de las niñas nunca dicen su nombre $(45 \%)$, edad $(50 \%)$, datos de su escuela $(70 \%)$ y dónde residen $(72 \%)$.

El $82.9 \%$ de los hombres y $80 \%$ de las mujeres reciben solicitudes para conocerles en fotografías y $77.1 \%$ de los hombres y $75 \%$ de las mujeres, en la webcam. Un poco más de mujeres adolescentes que hombres adolescentes reportan recibir propuestas para conocerlas en persona y hablar por teléfono con ellas.

Las y los participantes que chatean o utilizan el Messenger, reciben distintas propuestas, siendo la principal la de noviazgo ( $57.4 \%$ en las mujeres y $51.8 \%$ en los hombres). Es muy notable que sean las niñas (38\%) más que los niños (5.4\%) quienes reportan que los autores de esas solicitudes son hombres menores de edad. Un porcentaje menor pero similar de niños y de niñas (14.3 y 18.0, respectivamente) dice que son desconocidos quienes hicieron esas propuestas.

b) La producción de imágenes sexualizadas de niñas, niños y adolescentes. El $76.9 \%$ de las y los participantes reporta tener celular propio (55 hombres y 58 mujeres). La mayoría de éstos usa sus celulares para oír música. Sin embargo, llama la atención una diferencia estadísticamente significativa entre niños y niñas (cuadro 3): más niños $(25 \%)$ que niñas $(3.4 \%)$ reporta usar el teléfono celular para ver imágenes o videos de personas desnudas.

Hay un poco más de niños (23.6\%) que de niñas $(17.2 \%)$ que toman fotos o videos de compañeras/os sin que éstos se den cuenta (cuadro 3).

Porcentajes muy altos de niños y de niñas han tenido problemas por distraerse con el celular e interrumpir las clases. El $63.6 \%$ de los hombres y $60.3 \%$ de las mujeres reporta que ha tenido problemas por utilizar el celular en la escuela. En el cuadro 4 se aprecia que los principales problemas reportados son: el distraerse $(82.8 \%$ de los hombres y $68.6 \%$ de las mujeres) e interrumpir la clase ( $54.3 \%$ de los jóvenes y $45.7 \%$ de las mujeres). Aquí se observa otra diferencia estadísticamente significativa: más

Cuadro 3. Usos del teléfono celular. Comparación por sexo

\begin{tabular}{lcc}
\hline & $\begin{array}{c}\text { Hombres } \\
(\mathrm{n}=55)\end{array}$ & $\begin{array}{c}\text { Mujeres } \\
(\mathrm{n}=58)\end{array}$ \\
\hline $\begin{array}{l}\text { Tomar fotos o videos de compañeras } \\
\text { y compañeros sin que se den cuenta }\end{array}$ & $23.6 \%$ & $17.2 \%$ \\
$\begin{array}{l}\text { Ver imágenes o videos de personas } \\
\text { desnudas }\end{array}$ & $25.4 \%$ * & $3.4 \%$ \\
Oír música o chistes & $85.4 \%$ & $91.4 \%$ \\
Grabar peleas de compañeros & $45.4 \%$ & $32.7 \%$ \\
\hline${ }^{*} p<.05$. & &
\end{tabular}


Cuadro 4. Usos del teléfono celular que causaron problemas dentro de la escuela. Comparación por sexo

\begin{tabular}{lcr}
\hline & $\begin{array}{c}\text { Hombres } \\
(\mathrm{n}=35)\end{array}$ & $\begin{array}{c}\text { Mujeres } \\
(\mathrm{n}=35)\end{array}$ \\
\hline Distraerse en la escuela & $82.8 \%$ & $68.6 \%$ \\
Incumplir las clases & $54.3 \%$ & $45.7 \%$ \\
Tener pornografía & $8.6 \%$ & $2.8 \%$ \\
Grabar peleas de compañeros & $60.0 \% *$ & $25.7 \%$ \\
\hline
\end{tabular}

${ }^{*} p<.05$.

niños $(60 \%)$ que niñas $(25.7 \%)$ han tenido problemas por grabar peleas con su celular. La mayor sanción reportada por las y los participantes por usar el celular fue el retiro del mismo (51.4\% de las mujeres y $68.6 \%$ de los hombres). El $61.5 \%$ de la población en general reporta que conoce a alguna persona con imágenes en su celular de personas posando desnudas, siendo los celulares de las amigas y amigos (reportado por el 65\% de las mujeres y $55.8 \%$ de los hombres), así como los celulares de las y los compañeros (señalado por $62.5 \%$ de las mujeres y $62.8 \%$ de los hombres) aquellos que más portan dichas imágenes. Llama la atención que un poco más de hombres que mujeres reportaron que en su celular había esas imágenes (cuadro 5).

El $53.1 \%$ de la población (35 hombres y 43 mujeres) reportó conocer a algún amigo o amiga fotografiado o video-grabado con un celular. La mayoría de las niñas (65.1\%) y de los niños (65.7\%) dice que las personas fotografiadas estaban jugando, y más niñas (79\%) que niños (57\%) dijeron que estaban divirtiéndose. En el cuadro 6 se observa que más de la mitad de los niños (65.7\%) y de las niñas (53.5\%) dijo que estaban peleando. Un porcentaje similar de niñas y de niños señaló que las personas fotografiadas estaban borrachas (32.5\% y 34.3\%, respectivamente). Más niños que niñas dijeron que se besaban $(28.6 \%$ y $11.6 \%$, respectivamente) y exhibían sus cuerpos (17.1\% y $4.6 \%$, respectivamente).
Cuadro 5. Adolescentes reportados como portadores de imágenes de personas desnudas

\begin{tabular}{lcc}
\hline & Hombres & Mujeres \\
\hline Amistades & $55.8 \%$ & $65.0 \%$ \\
Compañeros & $62.8 \%$ & $62.5 \%$ \\
De mi propiedad & $16.3 \%$ & $12.5 \%$ \\
\hline
\end{tabular}

Cuadro 6. Actividades que realizaban las y los jóvenes fotografiados o videograbados

\begin{tabular}{lcc}
\hline & $\begin{array}{c}\text { Hombres } \\
(\mathrm{n}=35)\end{array}$ & $\begin{array}{c}\text { Mujeres } \\
(\mathrm{n}=43)\end{array}$ \\
\hline Estaban borrachos & $34.3 \%$ & $32.5 \%$ \\
Peleaban & $65.7 \%$ & $53.5 \%$ \\
Se besaban o acariciaban & $28.6 \%$ & $11.6 \%$ \\
Exhibían sus cuerpos & $17.1 \%$ & $4.6 \%$ \\
\hline
\end{tabular}

El promedio de edad de los amigos fotografiados o video-grabados es de 13 años de edad. Las principales actitudes que tomaron estas personas cuando se enteraron de esas fotos fue reír $(57.1 \%$ y $65.1 \%$ en hombres y mujeres, respectivamente), sin embargo un porcentaje importante de niños (34\%) y de niñas (24\%) dijo que se enojó, y una minoría dijo que los acusó (14\%) y pelearon $(14 \%)$.

Las principales personas que tomaron las imágenes fueron los amigos y conocidos; se observa que el $22.8 \%$ de los hombres y $16.3 \%$ de las mujeres reporta que estas personas fueron desconocidas completamente.

En la figura 1 se observa que las imágenes obtenidas se utilizaron para compartirlas con los amigos (reportado por el $77.1 \%$ de los hombres y el $62.8 \%$ de las mujeres). Muchos dijeron borrarlas (señalado por $54.3 \%$ de los hombres y $41.9 \%$ de las adolescentes). Pero otros las subieron a Internet (34.3\% hombres y $37.2 \%$ mujeres), las coleccionaron (34.3\% hombres y $14.0 \%$ mujeres) y una minoría las vendió (8.6\% hombres y $2.3 \%$ mujeres).

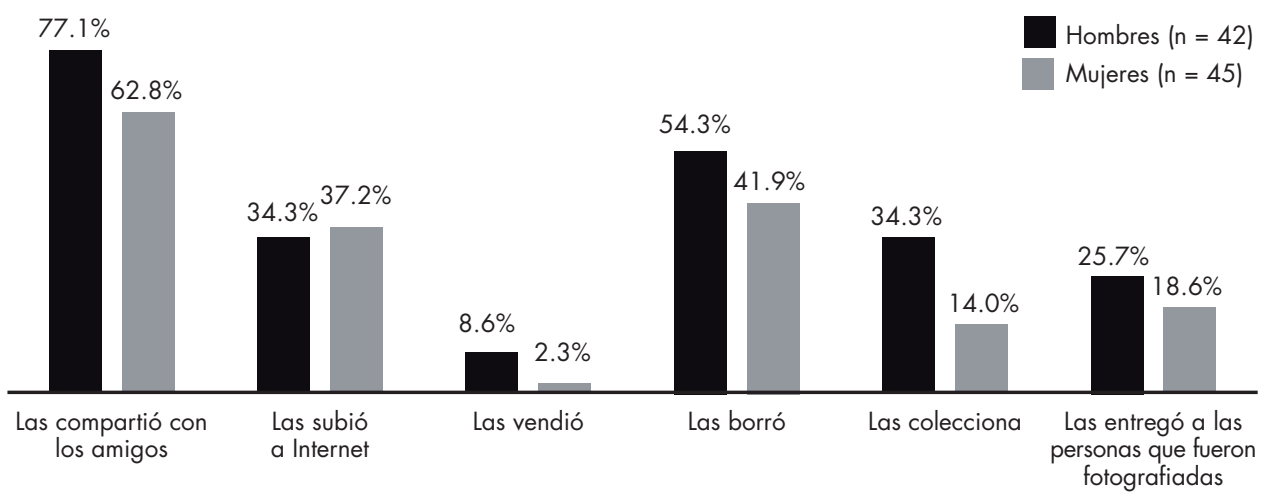

Figura 1. Usos de las imágenes obtenidas mediante teléfono celular. Comparación por sexo. 


\section{DISCUSIÓN Y CONCLUSIONES}

Parte de los resultados aquí expuestos revelan que las niñas y niños mexiquenses hacen pública información verídica de su persona (alrededor del 70\%) e interactúan con desconocidos en Internet (alrededor del 64\%). Estos porcentajes parecen superiores a la media europea con un perfil público de acceso irrestricto en las redes sociales (57 \%) así como a la media europea que interactúa con desconocidos $(34 \%) \cdot{ }^{2-6}$

Aunque los resultados obtenidos no incluyen casos de enganchamiento en línea atribuibles al uso de un perfil público en las redes sociales y a la interacción con desconocidos, tales prácticas están presentes en las muestras aquí abordadas y pueden ser consideradas indicadores de navegación insegura en la red de Internet. Ingenieros en sistemas de seguridad informática, ${ }^{20,21}$ organismos internacionales y de la sociedad civil a favor de los derechos de los niños y niñas, ${ }^{1,8}$ agrupamientos policiales contra delitos cibernéticos, ${ }^{22}$ entre otros especialistas, señalan que el acceso irrestricto a la información personal en las redes sociales y la interacción con desconocidos en la Internet, incrementa la probabilidad de sufrir distintos delitos cibernéticos, incluida la explotación sexual.

Las niñas y niños hacen su perfil público en las redes sociales para estar vigentes en el imaginario colectivo de todos sus conocidos, incluidos exnovios/as y desconocidos. Niñas y niños de la misma generación y escuela aquí abordada, ${ }^{23}$ dijeron en distintos grupos focales que hacían pública y actualizaban información verídica de su persona en las redes sociales, esperando que fueran comentadas y opinadas por sus conocidos (amigos, familiares cercanos y distanciados, ex novios y ex amigos), e incluso desconocidos. Todo esto les permite a las adolescentes calibrar su popularidad, saber cómo son vistas y estimar qué tanto pueden sentirse parte de los demás.

Niñas y niños interactúan con conocidos y desconocidos en busca de estimación en internet. En los chats es común que estos últimos quieran conocerles por foto o a través de la webcam. ${ }^{23}$ También son comunes las propuestas de noviazgo y el acoso sexual de conocidos y desconocidos. Según los resultados aquí reportados, la mayoría de las niñas que chatea no proporciona datos verídicos de su persona; sin embargo, resultados de carácter cualitativo indican que eso puede cambiar después de algunos días de interacción. ${ }^{23}$ Adolescentes de la misma generación y escuela dicen que después de varias veces de interactuar con un desconocido, le pueden proporcionar información verídica de su persona si notan que él/ella se interesa en sus problemas y gustos y es detallista, incluso algunas han consentido citas cara a cara con él. Ellas manifiestan que les entusiasma y emociona acudir al encuentro, pero lo consideran un riesgo porque creen que las pueden secuestrar o robar. Procuran ir acompañadas de otras amigas y antes del encuentro, espiar al contacto para corroborar que corresponda con la edad y la imagen proyectada en línea. Ellas dijeron que si él no cumple este requisito, evitan el encuentro. $\mathrm{Al}$ parecer los temores de las adolescentes no son exagerados, la policía cibernética mexicana tiene conocimiento de cientos de niñas y niños explotados sexualmente después de haber proporcionado información de su persona a desconocidos en Internet, intimado en línea y asistido a encuentros cara a cara con ellos. ${ }^{22}$

Por distintas razones (religiosas, morales, de desigualdad de género, de derechos humanos, de buen gusto, etc.), la pornografía no es considerada apta para menores de edad en México. Sin embargo nuestros resultados revelan que más niños (25\%) que niñas (3.4\%) ven imágenes o videos de personas desnudas (pornografía) en su teléfono celular. Esta práctica parece normalizada entre los escolares, ya que el $61.5 \%$ de la población en general reporta que conoce a algún escolar con imágenes de personas desnudas en su celular.

Desde una perspectiva sociocultural, la normalización del consumo de pornografía durante la adolescencia ocurre en contextos socioculturales donde prevalecen discursos y prácticas que asumen tácitamente que la adolescencia masculina es un periodo "caliente por naturaleza". ${ }^{23,24}$ Una etapa onanista y morbosa, gobernada por "hormonas fuera de control" o "instintos sexuales" experimentados como deseos impersonales, obsesionados con algunas parcialidades corporales de las mujeres.

Los adolescentes se apropian parcial o totalmente de los discursos y prácticas culturales de la "calentura adolescen$t^{\prime \prime},{ }^{23}$ los combinan e integran, para consumir pornografía a su manera, ya sea en privado o de manera pública. Varios adolescentes dicen que la "porno" les puede producir asco, pero también ayudarlos para excitarse y masturbarse en privado, conocer posiciones sexuales y ver mujeres desnudas. ${ }^{23}$ Además los adolescentes consumen pornografía de manera colectiva para demostrar públicamente su hombría en las escuelas. Se trata de una demostración teatralizada, espontánea y grotesca de su "hombría calenturienta", ${ }^{23}$ en la cual resulta común ver a pequeños grupos de niños arremolinarse para ver pornografía en la pantalla de un teléfono celular. Mientras ellos ven pornografía simulan excitarse (gimen, gritan, jadean), masturbarse o practicar alguna posición sexual por detrás de un compañero descuidado, mientras otros ríen a carcajadas o hacen comentarios morbosos sobre las exageraciones de la pornografía. Esta no es la única demostración de hombría "calenturienta". Las niñas se quejan de los niños a los que llaman "morbosos" porque ellos suelen hablar en doble sentido sexual, buscan ver los calzones de las niñas que suben las escaleras, manosearlas, tomarles foto por debajo de sus faldas, besarlas, etc.

Por otro lado los escolares usan los celulares para producir imágenes de compañeras y compañeros jugando y divirtiéndose, pero también cuando pelean, están borrachos, se besan o exhiben sus cuerpos. Ellos comparten esas imágenes con los demás, incluso las suben a la red de Internet y en algunos casos las venden. 
De acuerdo con entrevistas y grupos focales a adolescentes de la misma generación y escuela, ${ }^{23}$ muchas de estas imágenes se producen en el "desmadre". Esta es una práctica cultural común entre niñas y niños de escuelas secundarias, la cual se rige por las reglas "todos contra todos" y "el que se lleva se aguanta". ${ }^{25}$ Hay desmadres que combinan el júbilo colectivo con las transgresiones sexuales entre niños y niñas (manoseos, bajada de faldas y pantalones, bailes eróticos, entre otros). Algunas veces este tipo de "desmadre" es video-grabado con celulares y sus participantes parecen estar de acuerdo con ello: hablan, sonríen, se alcoholizan, se besan y manosean, exhiben sus cuerpos mientras bailan eróticamente frente a la cámara del celular. En medio del júbilo colectivo algunas/os pueden consentir (aunque otras/os no) en que esas imágenes sean subidas a las redes sociales o incluso a You Tube. En cualquier caso, después de mirarse en la red de internet es común encontrar el arrepentimiento de algunas/nos y el enojo de otros. Entonces las imágenes les parecen vergonzosas y humillantes, ya sea porque aparecen sexualizadas (tomas fijas de sus asentaderas, piernas, senos, ropa íntima), o su imagen es humillante (alcoholizados, apaleados, defecando, vomitando, etc.). Como consecuencia las personas ofendidas pueden enojarse y pelear con quienes produjeron y subieron esas imágenes a la Internet. En caso de que esas imágenes sean vistas por familiares, maestros y/o vecinos, las niñas pueden experimentar la estigmatización, baja autoestima y depresión. ${ }^{23}$

Puesto que los resultados aquí reportados se restringen a muestras no representativas del Estado de México, son insuficientes para legitimar la inclusión del tema de la seguridad en línea para niños y niñas en la agenda de las políticas públicas gubernamentales. Para tal efecto, es necesario desarrollar investigaciones epidemiológicas acerca de los usos de Internet y los riesgos asociados en muestras representativas de estudiantes a nivel municipal y estatal así como impulsar las investigaciones etnográficas y cualitativas que permitan la comprensión profunda y la evaluación rápida de los usos de las nuevas tecnologías y el papel de la agencia adolescente ante riesgos asociados a situaciones de explotación sexual en pequeñas muestras de escolares, profesores, padres de familia, etc.

\section{AGRADECIMIENTOS}

Los autores agradecen al Sistema Estatal para El Desarrollo Integral de la Familia Estado de México (DIFEM), y de manera particular a la doctora Patricia Isabel Tella Rosas, Jefa del Departamento de Menores Trabajadores Urbano Marginales del DIFEM, por su confianza y apoyo en todo el proceso de esta investigación.

\section{REFERENCIAS}

1. Cabello P, Fernández I. La tecnología en la preadolescencia y adolescencia. Usos, riesgos y propuestas desde los y las protagonistas. Brasil: Save the Children; 2008.
2. Garmendia M, Garitaonandia C, Martínez G, Casado M. Riesgos y seguridad en internet: Los menores españoles en el contexto europeo. Universidad del País Vasco/Euskal Herriko Unibertsitatea, Bilbao: EU Kids Online; 2011.

3. Hasebrink U, Livingstone S, Haddon L, Ólafsson K. Comparing children's online opportunities and risks across Europe: Cross-national comparisons for EU Kids Online. LSE, Londres: EU Kids Online; 2009.

4. Livingstone S, Haddon L, Görzig A, Ólafsson K. Risks and safety on the internet: The perspective of European children. Initial Findings. LSE, Londres: EU Kids Online; 2010.

5. Lobe B, Livingstone S, Haddon L. Researching children's experiences online across countries: Issues and problems in methodology. LSE, Londres: EU Kids Online; 2007.

6. Mascheroni G, Ponte C, Garmendia M, Garitaonandia C et al. Comparing online risks for children in south-western European Countries: Italy, Portugal and Spain. Media Cultural Politics 2010;6:25-44.

7. Mitchell k, Finkelhor D, Wolak J. Unwanted sexual material on the internet. A national survey of risk, impact, and prevention. Youth Society 2003;34:330-358.

8. Muir D. La violencia contra los niños en el ciberespacio. Tailandia: ECPAT International; 2005.

9. Noll J, Shenk C, Barnes J, Putnam F. Childhood abuse, avatar choices, and other risk factors associated with Internet-initiated victimization of adolescent girls. Pediatrics 2009;123:1073-1078.

10. Quayle E, Loof L, Palmer T. El uso de niños, niñas y adolescentes en pornografía y la explotación sexual de menores en Internet. Brasil: ECPAT Internacional; 2008.

11. Wolak J, Mitchell K, Finkelhor D. Youth Internet users unwanted and wanted exposure to online pornography in a national sample of youth internet users. Pediatrics 2007;119:247-257.

12. Ybarra M, Mitchell K. Exposure to Internet pornography among children and adolescents: A national survey. Cyberpsychology Behavior 2005;5:473-486.

13. Asociación Mexicana de Internet. Hábitos de los usuarios de Internet en México 2010. (última búsqueda marzo 2012) http://www.slideshare. net/diplomadocom/estudio-de-los-hbitos-de-los-usuarios-de-interneten-mxico-2010

14. González CA, Cárdenas R. Homicidios en la población menor de cinco años en México 1992-2001. Papeles de Población, 2004;40:247-275.

15. Fiscalía Especial para la Atención de Homicidios Dolosos Cometidos Contra la Mujer, Estado de México. Informe Ejecutivo de actividades 2006. (última búsqueda marzo 2012) http://www.edomexico.gob.mx/ pgjem/boletines/boletines07/25enero07.htm

16. Instituto Ciudadano de Estudios sobre Inseguridad. Tercera Encuesta Nacional sobre Inseguridad 2005. (Última búsqueda marzo 2012) http://www.icesi.org.mx/documentos/encuestas/encuestasNacionales/ ensi3_resultados_nacional_y_entidad_federativa.pdf

17. Instituto Ciudadano de Estudios sobre Inseguridad. Quinta encuesta sobre inseguridad nacional 2008. (Última búsqueda marzo 2012) http:// www.icesi.org.mx/documentos/propuestas/cuadernos_icesi.pdf

18. Instituto Nacional de Geografía y Estadística. Encuesta nacional sobre dinámica de las relaciones en los hogares, 2006. (Última búsqueda marzo 2012) http://www.inegi.org.mx/sistemas/tabuladosbasicos2/ TabGeneral.aspx?s=est\&c $=26245$

19. Pansters W, Castillo $H$, Violencia e inseguridad en la ciudad de México: entre la fragmentación y la politización. Foro Internacional 2007;189:577-615.

20. Borbón SJ. Redes sociales, entre la ingeniería social y los riesgos a la privacidad. Revista seguridad, defensa digital. 2012, Núm. 12. Dirección General de Cómputo y de Tecnologías de Información y Comunicación/SSI/ UNAMCERT, Universidad Nacional Autónoma de México. (última búsqueda mayo 2012) http://revista.seguridad.unam.mx/

21. Durán L JC. Los niños del Internet. Revista seguridad, defensa digital. 2010 Número 6. Dirección General de Cómputo y de Tecnologías de Información y Comunicación/SSI/UNAMCERT, Universidad Nacio- 
nal Autónoma de México (última búsqueda mayo 2012) http://revista. seguridad.unam.mx/numero-06/los-ni\%C3\%B1os-del-internet

22. Secretaría de Seguridad Pública. Cuarto Informe de Labores. Septiembre 2003-julio 2004. (Última búsqueda mayo 2012) http://www.lib. utexas.edu/benson/lagovdocs/mexico/federal/seguridadpublica/informe4-2003-2004.pdf

23. Gutiérrez R, Vega L, Rendon E. Riesgos de explotación sexual de ado- lescentes usuarios de las nuevas tecnologías. UNICEF-México/Santander Serfín México, 2013.

24. Gutmann MC. La "falocedad" de continuos: salud reproductiva entre los adolescentes de Oaxaca de Juárez. Estudios Sociales 2005;26:118-143.

25. Saucedo C. Estudiantes de secundaria. Sus apropiaciones de recursos culturales para recrear su condición como jóvenes en la escuela. Revista Mexicana Investigación Educativa 2006;29:403-429.

Artículo sin conflicto de intereses 